\title{
CAN EXTENDED CURRICULUM PROGRAMMES BE IMPROVED THROUGH ENGAGEMENT WITH STUDENTS USING APPRECIATIVE INQUIRY?
}

\author{
N. A. Ogude* \\ Campus Dean \\ e-mail: Nthabiseng.Ogude@up.ac.za
}

\section{J. Meyer*}

Senior Faculty Student Advisor

e-mail: Ida.Meyer@up.ac.za

\section{J. Mwambakana*}

Head of Academic: Foundation Programmes

e-mail: Jeanine.Mwambakana@up.ac.za

\section{N. E. Mthethwa*}

Research Assistant

e-mail: Nosipho.Mthethwa@up.c.za

*University of Pretoria, Mamelodi Campus

Mamelodi, Pretoria, South Africa

\section{ABSTRACT}

This research involves eight students at the University of Pretoria who identify with the Bachelor of Science (BSC) and the Bachelor of Commerce (BCom) Extended Curriculum Programmes (ECPs). The study reports on the use of Appreciative Inquiry (AI) to determine how these students describe the best aspects of the programmes and the attributes that they developed in order to succeed. The aim was to extrapolate the findings to develop an improvement plan informed by students' perspectives. The narratives from semi-structured interviews conducted during the Discovery and Dream stages of the modified Appreciative Inquiry 4-D process are reported. Six views emerged: sense of family and belonging; peer mentoring and support networks; coping with failure and developing self-efficacy; the underdog phenomenon, self-motivation and support for mainstream students; the student advising model; and extended curriculum programmes as a first option. In the Design phase, these views will be incorporated to formulate an improvement plan for the programmes.

Keywords: Appreciative Inquiry, extended curriculum programmes, off-site provision, peer learning, self-motivation and self-efficacy, stigmatisation 


\section{BACKGROUND}

Access Programmes are university programmes that are designed to accommodate students from disadvantaged academic backgrounds who are not adequately prepared for university (Rollnick 2010). Extended Curriculum Programmes (ECPs) are a type of the Access Programmes in which students are transitioned into tertiary education by incorporating modules that are in line with the mainstream academic programmes. Extended Curriculum Programmes are thus credit bearing, and students enter the mainstream after the extended phase of their degree. Other types of Access Programmes include the Foundation Programmes and the Augmented Programmes. Regarding the Foundation Programmes, students complete a year of non-credit bearing modules that are separate from the mainstream academic programmes. Augmented Programmes are a complete modification of the entire academic programme, which enables students to complete a modified degree programme over an extended period (Rollnick 2010).

The Mamelodi Campus of the University of Pretoria has been offering ECPs since 2008. Currently, three BSc programmes, namely Mathematical Sciences, Physical Sciences and Biological and Agricultural Sciences are offered by the Faculty of Natural and Agricultural Sciences. A BCom Extended Programme is offered by the Faculty of Economic and Management Sciences. The admission requirements are lower for the programmes than for the mainstream programmes since the majority of the students admitted on the campus do not meet the mainstream admission requirements.

At the University of Pretoria, the first phase of the extended programmes involves a time period of 18 months or three semesters, two of which are hosted at the Mamelodi Campus. These 18 months replace the first semester, and the students eventually complete the 3-year $\mathrm{BSc}$ and BCom degrees in four years.

The aim of the extended programmes is to enhance students' basic knowledge and skills so that by the time they complete this phase of study, they can work at the pace required of university students. Furthermore, students who embark on one of these programmes receive dedicated support in order to bridge the gap between school and higher education.

Due to the success of the extended curriculum programmes over the past decade, the university aims to increase its focus and determine areas for improvement from an institutional, curricular and student perspective. The objective is to ensure that students who commence their studies via this academic pathway graduate in minimum time.

As the first step towards improvement of the programmes, it was necessary to evaluate past successes and formulate appropriate research questions that would inform a renewed focus and the injection of more resources. Of particular concern for the researchers and the university 
is that in the literature, the programmes are still considered second class, and students are often stigmatised (Hlalele and Alexander 2012) because of the lower entrance requirements as compared to the mainstream programmes. Off-site provision of the programmes in many universities, including the University of Pretoria, still features predominantly among the challenges (Potgieter et al. 2015). Given these concerns, it became important to explore the student experiences and the nature of the stigmatisation, if any, from the student perspective. Moreover, the study of Potgieter et al. (2015) regarding the experiences of the first cohort of students reported that the students did not report stigmatisation and that there may be an emergence of acceptance of the programmes.

This study investigated the student experiences and whether there is indeed an emerging acceptance of the programmes and if so, what contributes to this acceptance and how the students cope with stigmatisation if present to develop attributes for success. This was done through eliciting the views of students that self-identify as having commenced their studies in the BSc Extended Curriculum Programme and have either graduated or are still studying. The ultimate aim was to extrapolate the findings to improve ECPs at the University of Pretoria.

\section{INTRODUCTION}

The challenges that students experience when they transition from high school to university are internationally acknowledged phenomena (Kuh 1995; Tinto 2012; Wong and Yeung 2004). However, in the higher education system of South Africa, the problem is compounded by the legacy of institutionalised inferior education advocated for black people by the apartheid regime (Boekhorst and Britz 2004; Brown 2006; Mncwabe 1993); consequently, most of the students in South African ECPs are black students. The pervasive nature of this problem gave rise to concerted efforts to bridge the school-university gap over the past two and a half decades (Boughey 2005; Case, Marshall and Grayson 2013; Grayson 1997; HELTASA 2010; Inyathelo 2014; Mabizela 1994; Potgieter 2010; Rollnick et al. 1997).

ECPs have been widely used to close the broad school-university gap. The programmes develop students academically and psychologically for further studies through a unique curriculum structure that articulates with the mainstream programme. Currently, 23 of the 26 higher education institutions, including the University of Pretoria, receive designated redress funding from government to offer the different types of Access Programmes, which include extended, augmented and foundation programmes (HELTASA 2010; Rollnick 2010).

Most of the teaching and learning takes place in small groups of fifty individuals. The academic content is delivered at a slower pace than in the normal programmes, so students have more time to engage with the subject content (Engelbrecht, Harding and Potgieter 2014). 
Additional modules such as language and study skills and academic information management are offered, and extra support through career guidance and counselling is provided. Besides attending smaller classes, the students also attend lectures in large groups to prepare them for the transition to the mainstream. A wide variety of teaching and learning methods are used to deliver the content.

Although major academic and non-academic innovations have been developed to support the programmes, the initial stigma that has been associated with the programmes since their emergence in the 1980s persists. This article alludes to the stigma associated with the programmes in terms of students having not met the academic requirements for their first choice in the mainstream. This is further complicated by the off-site provision mentioned earlier.

The purpose of this study is to elicit student experiences using Appreciative Inquiry (AI) and in the process, contribute to addressing two of the most vexing problems that pose a dilemma for the future of ECPs. This study solicited positive experiences from students who self-identified with this academic pathway and who have developed attributes that have enabled them to overcome the challenges and succeed in their studies. The latter was achieved through a co-creation process between management and students, guided by a modified 4-D AI approach (San Martin and Calabrese 2011) that incorporated a fifth stage, the Definition phase (Frantz, Rhoda and De Jongh 2013).

\section{LITERATURE REVIEW}

Alternative academic access programmes that address the high school-university gap in Science, Technology, Engineering and Mathematics are commonplace South African higher education institutions (Case, Marshall and Grayson 2013; Chetty and Vigar-Ellis 2012). The work done has given rise to a rich and dynamic research field of academic development that focuses on closing the gap between high school and university, which is characterised by conceptual discontinuities and non-cognitive factors collectively referred to in the literature as transitional issues (Case, Marshall and Grayson 2013). Certain studies have focused on other aspects such as social justice and inclusion (Hlalele and Alexander 2012). Several longitudinal studies have reported on the efficacy of the programmes and their contribution to the development of science capacity for economic development (Downs 2005; Mathews 2012).

Despite these successes, there are enduring concerns about the ability of access programmes to address the complex problem of the underrepresentation of the black population. Besides the efficiency of the programmes, two widespread concerns in the literature are the apparent stigma associated with the programmes and the off-site provision. According to Hlalele and Alexander (2012), access programmes unavoidably give students a label due to the 
lower entrance requirements. Hlalele and Alexander (2012) also describe off-site provision as a significant contributor to the stigma that entrenches disadvantage further since the students are socially removed from other students, including senior students, resulting in a perceived impoverished university experience. In addition to the overall experiences of the students, the manner in which these two aspects manifested among previous students enrolled in the ECPs at the University of Pretoria and students who self-identified with this academic pathway were thus of particular interest in this study.

Engelbrecht, Harding and Potgieter (2014) conducted an evaluation of the successes of the 2008 cohort of the BSc Extended Curriculum Programme at the University of Pretoria using five quantitative criteria, namely retention, completion rate, migration to other faculties, comparison with other institutions and enrolment in graduate studies. They found that 15 per cent of students completed in minimum time, the attrition rate was 43 per cent across the four-year science degree programme and the eventual degree-completion rate of students, including those that migrated to other science-related faculties, was about 50 per cent (ibid.). Their overall conclusion was that the programme is reasonably successful in regard to retention and completion rate in comparison with similar programmes offered at the University of the Witwatersrand and the University of Kwa-Zulu Natal (Engelbrecht, Harding and Potgieter 2014).

The above quantitative study was complemented by a qualitative study of the same cohort of students conducted by Potgieter et al. (2015). This study investigated: (i) the challenges that students encountered upon transition to the mainstream programme; and (ii) the perceptions of students categorised as good, moderate or poor performers (ibid.). Overall, across performance bands, the students reported positive perceptions on the structure and other features of the academic programme such as the counselling and student advisory services. The authors concluded the paper by confirming key trends: (i) extended curriculum programmes offer positive experiences and both academic and non-academic gains; (ii) the intensity and volume of work and the smaller group size were received positively; and (iii) isolation from the mainstream remains a problem (Potgieter et al. 2015). Unlike previous studies, the students interviewed did not experience stigmatisation. The authors recommended that this latter aspect be investigated further because it demonstrates the emergence of acceptance of the programmes (ibid).

The current study builds on the strengths identified by Potgieter et al. (2015). In particular, the researchers wish to harness the emergent positive disposition of students for the continuous improvement of the programmes. It is believed that an AI framework (San Martin and Calabrese 2011) best suits the purpose of the study since the investigation sought to demonstrate that 
positive experiences of successful students can provide new insights into the continuous improvement of the programmes.

Appreciative Inquiry is a form of action research that attempts to help individuals, groups, organisations and communities to create a new vision for themselves based on a positive understanding of their past experiences (San Martin and Calabrese 2011). Although originally intended for organisational change management, and often used for strategic planning processes for universities and colleges (Finegold, Holland and Lingham 2002), AI is increasingly being applied in other contexts and specifically in educational research (Frantz, Rhoda and De Jongh 2013). There are several AI models derived from the original 〈Four D〉 process of David Cooperrider (Keefe and Pesut 2004; Whitney and Schau 1998). These include the aspects of: (i) discovery (appreciating what is and how it can be used); (ii) dream (imagining what might be); (iii) design (determining what should be); and (iv) delivery/ destiny (creating what will be).

In using the AI approach, the researcher guides participants through the four distinct stages. Because it is action research, the AI researcher acts as both participant and observer, being fully immersed with the participants as the AI 4-D cycle (Doveston 2007) is facilitated. In this study, the researchers used a model similar to the one used by Frantz, Rhoda and De Jongh (2013), which included an additional aspect - Definition (establishing the focus and scope of the inquiry). In the current study, three researchers and a research assistant developed the research questions.

\section{RESEARCH QUESTIONS}

The study aimed to address the following questions:

1. How do students previously enrolled at the Mamelodi Campus describe their best experiences?

2. Is there an emerging acceptance of the programmes, and what contributes to this acceptance?

3. What are the benefits of being part of the programmes offered at the Mamelodi Campus?

4. How could the findings be extrapolated to improve the offerings of ECPs at the University of Pretoria?

These questions were rephrased in line with an AI approach for the Discovery phase as follows:

1. What were your experiences in the transition from high school to university? From your experience, what works in the ECPs offered at the Mamelodi Campus?

2. What did you like most about being part of the Mamelodi Campus, and how did others 
(staff and students) perceive you?

3. What are the benefits of starting your studies at the Mamelodi Campus as opposed to the Hatfield Campus?

For the Dream phase (imagining what might be), Question 4 was rephrased as follows:

4. Would you recommend students to follow this academic pathway?

\section{METHODOLOGY}

Ethics clearance was obtained from the University of Pretoria for the qualitative study, and all students involved signed an informed consent form. The students were designated as S1, S2, etc. to protect their identities.

\section{Research design}

The authors used a qualitative study design to facilitate the first three stages of a modified AI 4-D cycle (Definition, Discovery and Dream). The Definition phase was the additional phase of the modified 4-D cycle.

\section{Phase 1: Definition}

Invitations were sent to 20 students to attend a Saturday morning workshop to clarify the purpose of the study. The students were selected from the Student Support Services database of previous students who had volunteered to take part in extended programme activities on campus. Of the 12 students that attended the workshop, eight students (six graduates and two current) were able to commit to the entire process based on availability. The purpose of this stage was to establish a common understanding of the purpose of the research, namely the improvement of ECPs from a student perspective and thus, no research question was formulated for this phase of the research.

\section{Phases 2 and 3: Discovery and Dream}

Eight students attended two separate follow-up interviews that covered the Discovery and Dream stages. The first session was attended by six students, and the second by two students. In responding to the questions, students engaged in meaningful dialogue, drawing from personal experiences. One of the researchers conducted the interviews and the other two researchers took notes while a research assistant oversaw the audio and video recordings.

In the Discovery phase, the objective was to determine how students who identified with the extended academic pathway described their best experiences and how they came to accept 
the programme and benefit from it. The objective of the Dream phase was to have students make suggestions on how the extended programmes could be improved so as to formulate an improvement plan that would be addressed in the Design phase of the study.

\section{Profile of students interviewed}

Student (S1): Black female - PhD Candidate (Microbiology)

Student (S2): Indian female - Third-year MBChB

Student (S3): Black male - BSc Agricultural Economics. Employed as an incubation analyst Student (S4): Black female - BSc (Hons) Pharmacology. Employed as a clinical research assistant

Student (S5): Black male - BArch (Hons). Master's student

Student (S6): Black female - BSc (Hons) Geology. Employed

Student (S7): Black female - BSc Quantity Surveying. Final-year student

Student (S8): Black male - BCom Business Management. Self-employed

\section{Data analysis}

Data were collected from the recorded transcriptions of the semi-structured interviews and from the researchers' notes. The positive affirming nature of AI, in which people discover and then build on root causes of successes rather than dissect problems, was used as the basis for analysis of the data. Data analysis involved transcribing the tape recordings and identifying major themes. The transcribed interviews yielded a total of 18469 words.

\section{Limitations of the study}

Generalisation of the results of this study is limited since the focus was solely on previous ECP students that had been purposefully selected and had previously showed keen interest in activities relating to the extended programmes after they proceeded to the mainstream. However, it is believed that the findings are significant for further development of extended curriculum programmes.

\section{RESULTS AND DISCUSSION}

Five dominant themes emerged during the Discovery phase of the interviews while one theme emerged during the Dream phase of the interviews. Table 1 summarises the findings.

Table 1: Summary of phases 2 and 3 of Appreciative Inquiry

\begin{tabular}{|l|l|l|}
\hline Phases of appreciative inquiry & Research question & Themes \\
\hline Definition phase & None & Not applicable \\
\hline Discovery phase & 1. How do previously enrolled & $\bullet$ Sense of family and belonging \\
\hline
\end{tabular}




\begin{tabular}{|c|c|c|}
\hline Phases of appreciative inquiry & Research question & Themes \\
\hline & $\begin{array}{l}\text { ECP students best describe } \\
\text { their experiences at Mamelodi } \\
\text { Campus? }\end{array}$ & $\begin{array}{ll} & \text { Peer mentoring and support } \\
\text { networks } \\
\text { - } \\
\text { Coping with failure and } \\
\text { developing self-efficacy }\end{array}$ \\
\hline & $\begin{array}{l}\text { 2. Is there an emerging } \\
\text { acceptance of the } \\
\text { programmes, and what } \\
\text { contributes to this } \\
\text { acceptance? }\end{array}$ & $\begin{array}{l}\text { The underdog phenomenon - } \\
\text { self-motivation and support for } \\
\text { mainstream students }\end{array}$ \\
\hline & $\begin{array}{l}\text { 3. What are the benefits of being } \\
\text { part of the programmes } \\
\text { offered at the Mamelodi } \\
\text { campus? }\end{array}$ & - $\quad$ The student-advising model \\
\hline Dream phase & $\begin{array}{l}\text { 4. How could the findings be } \\
\text { extrapolated to improve the } \\
\text { offerings of ECPs at the } \\
\text { University of Pretoria? }\end{array}$ & - $\quad$ ECPs as a first option \\
\hline
\end{tabular}

The findings gained from the rich and descriptive data from the interviews are presented in the order indicated in the table above.

\section{Discovery phase: Best experiences}

\section{Theme 1: Sense of family, group identity and belonging}

According to Hausmann, Schofield and Woods (2007), institutional commitment was highly influenced by the sense of belonging and served as a significant predictor of intention to persist. Hausmann, Schofield and Woods (2007) state that failing to achieve a sense of belonging can have negative consequences and thus, models of college-student persistence have often included elements of belonging. According to Hausmann, Schofield and Woods (2007), the most popular and researched model of student persistence is that of Tinto (1987), which theorised that assimilation of students into their social and academic college environment increases the likelihood of college retention.

The interviews revealed that students become part of a family, the University of Pretoria family.

S6: "The lecturers, student-support staff and students were all part of the caring family. It made you positive and helped me to focus when the rest of the world was caving in - like when my mother died."

The students' most positive experiences were associated with a sense of belonging and a caring environment, unlike their experiences with the Hatfield Campus, which they perceived as alienating. 
S2: "At Hatfield Campus, they don't really care about you. But here, we say no one gets left behind versus at Hatfield Campus where it's 'cut throat'."

Contrary to feeling isolated, S2 appeared to appreciate that the Mamelodi Campus provides a safe, non-intimidating environment in which one is not judged.

S2: "The fact that everybody at the Mamelodi Campus is all first years really helps. When you get to Hatfield Campus or to Med. Campus, there are second years and fifth years and people who have all fancy scrubs that intimidate you. The Mamelodi Campus is almost the safe environment that you can fumble."

The sense of family also contributed to overcoming disappointment. However, S1 acknowledged this to be a problem initially.

S1: "If you think about how you go to the Mamelodi Campus - and most of us feel like this - it's the end of the world. But then you have people who pick you up, and you go home and you motivate yourself. Then when you meet a challenge, it's no more a challenge. It's like 'Okay, I can do this'. I can do whatever I put myself to."

The University of Pretoria family extends to recognition and affirmation by some lecturers after transition to the Hatfield Campus.

S2: "Some of them (lecturers) still know me by name when they see me walking on Hatfield Campus. They like, 'How is it going? Are you still doing well?' It's so nice to know that you come from a family or a community that still cares about you even after you've left the place."

\section{Discovery phase: Best experiences}

\section{Theme 2: Peer mentoring and support networks}

The students that thrive in the programme seem to be committed and to develop certain adaptive strategies, thus adjusting to the programme. Peer mentoring and what the students refer to as the "buddy system" appear to be major contributors in this respect.

According to Kuh, Pike and McCormick (2011), peers can enhance the academic performance of both the mentees and the mentors. An interesting observation in the interviews of the students is that the mentoring programme is an organically evolving process that continues outside the formal mentoring programme when the students proceed to the mainstream of the university.

With a common goal for all to succeed, the students overcome the absence of senior students by learning from each other. 
S6: "There was no senior student to mentor me in the field of BSc Physical Sciences. However, I was able to identify students who mastered specific modules, and I challenged myself to interact with them and seek their assistance. I used to struggle with WTW143 until I consulted with top students in my class. Amazingly, by the end of the quarter, I was thriving, and my marks had improved."

The shared goal to achieve academic success is unlike the competitive high school environment.

Student S3 expresses this collaborative approach:

S3: "In high school, you have the top 10 that are like the best in the grade and it's a competition ... So you can't be going to ask for help from somebody who doesn't want you to be on top of them. At the Extended Programmes Campus [16], it's: We need to get this thing together. It is not about you or her; it's about all of us."

Surprisingly, the peer-mentoring system that commences when the students are at the Mamelodi Campus continues as they proceed to mainstream programmes and into postgraduate studies.

S1: "We were in different academic programmes, and when we got to main campus, some in genetics, some in biochemistry, but we carried each other to the point where even some of the people I went with in undergrad - some are doing their Master's - and we still say, 'Read my thesis for me, edit it for me'. We become a study group for life if I can say that."

\section{Discovery phase: Best experiences}

\section{Theme 3: Coping with failure and developing self-efficacy}

Engelbrecht, Harding and Potgieter (2014) report that students in ECPs experience obstacles that include constant feelings of failure for not being admitted into mainstream programmes. Lubben et al. (2010) cite inability to cope with failure as a major reason for dropout. Students in this study managed failure well and more importantly, did not allow it to define them.

S1: "A big one for me personally was learning how to handle failure, which you do not learn in school because everything is about your marks. Secondly, once you get to university, you learn you will fail at least one test, and if you don't know how to pick yourself up ...."

The Mamelodi Campus gave Student S7 the platform to realise that it is acceptable to begin again and to adopt a new approach in order to succeed.

S7: "I take failure in my stride, and I can use it when I speak to people that I failed this and this, but that wasn't what defined me. It's what I did after that defined who I am.” 


\section{Discovery phase: Emerging acceptance}

\section{Theme 4: The underdog phenomenon, self-motivation and support for mainstream students}

It is evident that there were times when the students felt that they were not in a good position to achieve success; they were at a disadvantage, and their chances were minimal. The students also acknowledged that initially, they were defensive about their position and always felt obliged to explain their placement at the Mamelodi Campus. However, with time, they realised that being at the Mamelodi Campus was a blessing and a perfect stepping stone since they were able to cope and obtain excellent marks as opposed to their friends on the main campus (S6). In addition, most of the students indicated that being looked down upon fuelled them to work harder and prove to critics and themselves that they can excel. Student S2 who proceeded to enrol for an $\mathrm{MBChB}$ degree summarises the feeling:

S2: "No one expects success from an underdog ... you kind of have that underdog title when you go into the Mamelodi Campus 'cos many people look down on you ... You are said to be in Grade 13!' If you ever find yourself being seen as an underdog, say you're an intern. Or another challenge when you are in the mainstream, you can say, 'But I was once an underdog, and I've done it before and I've overcome'."

Student S8 agreed, saying:

S8: "So when you are seen as an underdog, that self-motivation comes from within to say I've done that. I've conquered it. So what's this that lies ahead ... can be done."

The students went further, using their skills to support mainstream students. This was another unexpected finding.

S6: "The experiences I went through made me eager to help first years at main campus because I understood exactly what they are going through, and that gave me a platform to transfer some of the survival skills I was taught at the Mamelodi Campus. I advised them also to select elective modules using my knowledge on modules."

Finally, student S6 illustrated how she provided non-academic support:

S6: "One student lost her mother during the course of the year at the main campus. I was able to comfort her and give her some of the coping skills I was given at the Mamelodi Campus." 


\section{Discovery phase: Benefits of extended programmes}

\section{Theme 5: The student advising model, consultation and personality profiles}

Students experienced knowing their strengths and learning to overcome their weaknesses with more awareness of their identity. This increased their self-concept, which in turn, seemed to lead to higher feelings of self-efficacy. The authors are not aware of previous studies on how the provision of student-advising services contributes to the success of students in extended curricular programmes in South Africa. The Student Support services of the Mamelodi Campus and the student advisors, referred to as Student Advisor (SA1) and Student Advisor (SA2), appear to play a critical role in enabling students to feel part of the family. Student S2 expressed strong views in relation to personality profiles administered by the student advisors:

S2: "I'm such an advocate for this. I will lay my life down for this because you sort of have an idea as a person what you're strong at and what you're not at high school. As a child, because that is what you are when you get here, you still don't really want to deal with your weaknesses. So having someone like SA1 tell you these are your weaknesses and what you can do to work on them and realising that they can become your strengths is something that will allow you to find other weaknesses 'cos we not perfect'."

The students also felt that the consultations with the student advisors provided much-needed focus. Student S2 continued:

S2: "[Y]ou realise that student advising gives you direction, and direction is something that was needed at the Mamelodi Campus because if I didn't have direction I would feel like I'm floating. Then my goal wouldn't have been conceptualised. So having direction and getting the goal and then working toward it is that stepwise process that helps."

The students experienced that they continued to use the academic and study skills that they had learnt at the Mamelodi Campus when they transitioned into the mainstream. They reported that these skills enabled them to be focused, responsible, productive students that were able to prioritise and use their time effectively.

S5: "I've been struggling with time management. Even now, I am struggling with that aspect. But from the workshop we had with SA1, I learnt that prioritising is key. I mean, even now, if I do something, I sit and prioritise."

S7: "About the personality test results at Student Support (Mamelodi). It taught me who I am. I still use it, and it makes me pass modules first time that other people mostly fail. The Mamelodi Campus taught me higher level of thinking that they don't teach you at school, but you need for varsity." 
The student services also assist with bursary information, textbook schemes, off-site and university accommodation and feeding schemes so that students can concentrate on their academic progress.

S4: "Had I gone to Hatfield Campus first, ya, I don't know honestly. That's not to say that I'm a wreck or anything, but it's just varsity is real guys, it's hard. So ya, uhm - if you ask anyone who went to the Mamelodi Campus, if they know SA1, they would say 'Oh my gosh! She's helped me so much.' She touches so many people's lives and ya ... Whether it's finance, whether it's residence, whether it's just life, whether it's academics, she's an all-rounder."

The students also felt that the staff was approachable and friendly and formed a student-support network in which students were not judged. Students S6 and S8 referred to their experiences thus:

S6: "Goodness me, I always drop a tear when I think of the impact that the student-advice services had in both my academic and personal life."

S8: "I consulted three times. I used to copy the way other students studied. I did not trust my own methods until I consulted with SA1 and SA2 who helped me identify the kind of learner I am (visual) and the methods which [sic] I can deploy so that I can excel. This gave me confidence and the ability to work at my own pace and focus ... Many challenges would have defeated me if I did not consult."

The students that were interviewed all showed increased feelings of self-efficacy, which is important for the process of successful learning. Van Dinther, Dochy and Segers (2011) refer to self-efficacy as one of the key elements in the social cognitive theory that affects learning and motivation in students.

\section{Dream phase: Improvement of Extended Curriculum Programmes}

\section{Theme 6: ECPs as a first option}

The interviews in the Dream phase revealed that the students not only self-identified as having commenced their studies in an ECP but also showed commitment to advocating the programme actively. This further confirms that they overcame the stigma associated with the programme and were, in fact, proud to have followed this academic pathway.

In response to whether she would encourage others to follow this academic pathway, Student S6 responded:

S6: "Look, we have to start advocating for [sic] the Mamelodi Campus. Define what the Mamelodi Campus is. For instance, I was in the Mamelodi Campus, came to Hatfield Campus, graduated 
... it's not just learning in the township, basically, its learning a new community, a brand-new environment."

Student S3 suggested that they should be advocates for the programme, starting with high school students. This student envisaged the group having an office from which to operate:

S3: "And if we start from high school level, that 'Look, we have a very strong support structure' ... we speak of ourselves ... Up to a point where we can even get an office at the Natural and Agricultural. We need an office there."

Student S2 agrees and advocates a departure from the current practice:

S2: "There should be more information and a positive face. Even if it's one of us that goes there and says, 'Look, it's not the end of the world if you go to the Mamelodi Campus'. It's not you just going to a township, 'cos that's the perception that a lot of people have when they say you are going to do the four-year programme in the Mamelodi Campus."

Some of the students started to volunteer as advocates for the programme. Student S2 reflects on the experience:

S2: "Remember what we did for the Open Day and went to the Mamelodi Campus where parents could come and see the campus? That helped because all parents that I spoke to said 'I think this is a good idea'. So, if we can get the word out more and the positive stuff, its strengths ...."

Student S5 argued against the current marketing approach employed during open days in which one venue is used for both the BSc three-year and four-year programmes, and the latter is marketed as a fall-back position.

S5: "If we have our own gazebo there, and we go there and we say listen, these are our courses. These are the people that started here, whether they knew where they wanted to be or not ... they've moved on; they are graduates now. They have done it in record time, and they've got their degrees. So think about it as an option. Don't make it as if you fail, you can do this ... Make it an OPTION. Make it a good, viable option that people consider first hand."

The experiences in the Discovery phase appeared to contribute to students' progress and persistence in their studies and simultaneously enabled them to overcome stigmatisation and the sense of isolation arising from being separated from students on the main campus. One finding that emerged from the Dream phase was the students' wish for the ECPs to be developed into a first-choice option of study. This resulted from the positive outcomes that the extended programmes had produced throughout their academic, social and psychological development. 


\section{CONCLUSION}

The aim of this study was to establish whether ECPs can be improved through engagement with students using Appreciative Inquiry. Similar to the study of San Martin and Calabrese (2011), the line of inquiry was designed to collect data based on students' strengths and assets.

Phase one consisted of the Definition phase, phase two comprised the Discovery phase and the third phase incorporated the Dream phase. In the Definition phase, the students understood the aim and purpose of the research, the improvement of ECPs.

It was evident in the Discovery phase that the following had positive effects on students' academic, social and psychological development: a sense of family and belonging; peer mentoring and support networks; coping with failure and developing self-efficacy; the underdog phenomenon; self-motivation and support for mainstream students; and the student advising model. These aspects enabled them to adapt to university smoothly.

Students' experiences in the Discovery phase appeared to have contributed to progress and persistence in their studies and simultaneously enabled them to overcome stigmatisation and the sense of isolation arising from being separated from students on the main campus.

These experiences led to the Dream phase in which students wanted their peers to experience the positive effects of transitioning and adapting to university. The students considered themselves as fortunate and 'dreamt' of a way to develop the programmes into a first-choice option and to improve the programmes so that what they personally experienced could be formally implemented to assist other university undergraduates.

The identified six themes will be investigated to provide further ideas for improvement and ultimately, to develop an improvement plan during the Design phase. Ways to implement the plan will be explored in the Destiny phase.

The researchers are driven by the belief that similar to organisations, AI can enable the University of Pretoria to harness emergent positive views on ECPs in order to create shared positive images and achieve a co-constructed and desired future through discourse and anticipation towards improvement of the ECPs. It is believed that the student voice is critical to the co-creation of knowledge of the programmes.

Finally, this article opens a wider debate on how students' advocacy for ECPs can be a strong rallying point and an area of untapped potential in the higher education system of South Africa. It is contended that the sector may finally begin to experience an era in which the Access Programmes can be mainstreamed through students' advocacy rather than through government and universities only. 


\section{REFERENCES}

Baumeister, R. F. and M. R. Leary. 1995. The need to belong: Desire for interpersonal attachments as a fundamental human motivation. Psychological Bulletin 117(3): 497-529.

Boekhorst, A. K. and J. J. Britz. 2004. Information literacy at school level: A comparative study between the Netherlands and South Africa. South African Journal of Library and Information Science 70(2): 63-71.

Boughey, C. 2005. 'Epistemological' access to the university: An alternative perspective. South African Journal of Higher Education 19(3): 230-242.

Brown, K. 2006. New educational injustices in the 'new' South Africa: A call for justice in the form of vertical equity. Journal of Educational Administration 44(5): 509-519.

Case, J., D. Marshall and D. Grayson. 2013. Mind the gap: Science and engineering education at the secondary-tertiary interface. South African Journal of Science 109(7-8): 1-5.

Chetty, Y. and D. Vigar-Ellis. 2012. Understanding the needs of science access students for university support services. South African Journal of Higher Education 26(5): 908-925.

Doveston, M. 2007. Developing capacity for social and emotional growth: An action research project. Pastoral Care in Education 25(2): 46-54.

Downs, C. T. 2005. Is a year-long access course into university helping previously disadvantaged black students in biology? South African Journal of Higher Education 19(4): 666-683.

Engelbrecht, J., A. Harding and M. Potgieter. 2014. Evaluating the success of a science academic development programme at a research-intensive university. African Journal of Research in Mathematics, Science and Technology Education 18(3): 287-298.

Finegold, M. A., B. M. Holland and T. Lingham. 2002. Appreciative inquiry and public dialogue: An approach to community change. Public Organization Review 2(3): 235-252.

Frantz, J. M., A. J. Rhoda and J. De Jongh. 2013. Using appreciative inquiry to develop a research capacity development programme. South African Journal of Higher Education 27(1): 40-59.

Grayson, D. J. 1997 A holistic approach to preparing disadvantaged students to succeed in tertiary science studies. Part II. Outcomes of the Science Foundation Programme. International Journal of Science Education 19(1): 107-123.

Hausmann, L. R., J. W. Schofield and R. L. Woods. 2007. Sense of belonging as a predictor of intentions to persist among African American and white first-year college students. Research in Higher Education 48(7): 803-839.

HELTASA see Higher Education Learning and Teaching Association of Southern Africa.

Higher Education Learning and Teaching Association of Southern Africa. 2010. Success stories in foundation/extended programmes. HELTASA, 2010. http://www0.sun.ac.za/heltasa/file.php/ 1/Foundation/Final_Book.pdf(Accessed 23 April 2012).

Hlalele, D. and G. Alexander. 2012. University access, inclusion and social justice. South African Journal of Higher Education 26(3): 487-502.

Inyathelo. 2014. Student access and success: Issues and interventions in South African universities. Cape Town: Inyathelo, 2014. http://www.inyathelo.org.za/knowledge-services/inyathelopublications/view-all-publications-for-download/item/student-access-and-success-issues-andinterventions-in-south-african-universities-2014.html (Accessed 28 July 2014).

Keefe, M. R. and D. Pesut. 2004. Appreciative inquiry and leadership transitions. Journal of Professional Nursing 20(2): 103-109.

Kuh, G. D. 1995. The other curriculum: Out-of-class experienes with student learning and personal development. Journal of Higher Education 66(2): 123-155.

Kuh, G. D., G. R. Pike and C. McCormick. 2011. An investigation of the contingent relationship between learning community participation and student engagement. Research in Higher Education 52(3): 300-322. 
Lubben, F., B. Davidowitz, A. Buffler, S. Allie and I. Scott. 2010. Factors influencing access students' persistence in an undergraduate science programme: A South African case study. International Journal of Educational Development 30(4): 351-368.

Mabizela, M. 1994. Voices from first year students at UWC. In AD Dialogues 3, edited by B. Leibowitz and M. Walker, 23-46. Bellville: University of the Western Cape.

Mathews, M. 2012. B.Sc. graduate output - a success indicator of access programs at Walter Sisulu University. South African Journal of Higher Education 26(5): 1016-1032.

Mncwabe, M. P. 1993. Post-apartheid education: Towards non-racial, unitary and democratic socialization in the new South Africa. University Press of Amer.

Potgieter, M. 2010. Conceptual gain in first-year chemistry: Is the gap addressed effectively? ASSAf Mind the Gap Forum. Cape Town.

Potgieter, M., A. Harding, Q. Kritzinger, C. Somo and J. Engelbrecht. 2015. Reflections of science students on their experience of an academic development programme in South Africa: Part I. South African Journal of Higher Education 29(1): 108-131.

Rollnick, M. 2010. Identifying potential for equitable access to tertiary level science: Digging for gold. Milton Keynes: Springer Science \& Business Media.

Rollnick, M., M. K. Mphahlele, N. A. Ogude, G. Green, P. Huddle, P. Mahooana and M. White. 1997. A team work approach to workshop delivery for tutor development. Academic Development 3(2): 91-116.

San Martin, T. L. and R. L. Calabrese. 2011. Empowering at-risk students through appreciative inquiry. International Journal of Educational Management 25(2): 110-123.

Tinto, V. 1987. Leaving college: Rethinking the causes and cures of student attrition. Chicago: University of Chicago Press, 5801 S. Ellis Avenue, IL 60637.

Tinto, V. 2012. Enhancing student success: Taking the classroom success seriously. The International Journal of the First Year in Higher Education 3(1): 1-8.

Van Dinther, M., F. Dochy and M. Segers. 2011. Factors affecting students' self-efficacy in higher education. Educational Research Review 6(2): 95-108.

Whitney, D. and C. Schau. 1998. Appreciative inquiry: An innovative process for organization change. Employment Relations Today 25(1): 11-21.

Wong, E. K. P. and A. S. Yeung. 2004. Project Yi Jin: An alternative route to lifelong education in Hong Kong. International Journal of Lifelong Education 23(4): 351-353. 